\title{
Amide-based Disulfide Building Blocks for the Enlargement of the Solid Phase Peptide Synthesis for Molecular Diagnostics and Imaging
}

\author{
Braun $\mathrm{K}^{1 *}$, Wiessler $\mathbf{M}^{1}$, Komljenovic $\mathbf{D}^{1}$, Schrenk HH$^{1}$, Lorenz $\mathbf{P}^{1}$, Fleischhacker $\mathbf{H}^{1}$, Waldeck $\mathbf{W}^{2}$ and Pipkorn $\mathbf{R}^{3}$ \\ ${ }^{1}$ German Cancer Research Center, Department of Imaging and Radio Oncology, INF 280, D-69120 Heidelberg, Germany \\ ${ }^{2}$ German Cancer Research Center, Division of Biophysics of Macromolecules, INF 580, D-69120 Heidelberg, Germany \\ ${ }^{3}$ German Cancer Research Center, Central Peptide Synthesis Unit, INF 580, D-69120 Heidelberg, Germany
}

\begin{abstract}
Progress in genome and proteome research led to a deeper insight in differential gene expression processes. This required the use of sensitive and specific tools in diagnostics; also new promising patient-specific therapy attempts are conceivable. Nucleic acids were up till now a critical goal for diagnostic applications and therapeutic interventions, but in future they can serve as highly sequence-specific tools in molecular diagnostics. Examples for diagnostic Molecular Imaging modalities are the analysis of metabolic processes which can lead to customized therapeutic approaches ("Targeted Therapy"). The solid phase peptide synthesis SPPS is considered as an excellent tool in the individualized medicine with nucleic acids which increasingly play a key role as a drug. This requires new properties of the nucleic acid-based drugs, contiguous to the stability in biological systems, a high variability by combination with functional peptide-based molecules or with reformulated drugs or imaging components. The multifaceted application spectrum is dependent on the patients' individual differential gene expression profiles or on the medical questionnaire. Here we show a new synthesis strategy able to circumvent ligations steps and to enhance the yields in the SPPS technology by use of a novel disulfide-containing monomer. This molecule acts as a disulfide linker which can overcome the common occasional losses occurring during established coupling reactions, like disulfide-bridge formations.
\end{abstract}

Keywords: Disulfide Building Block functionalization; Click Chemistry; Solid phase peptide synthesis; Molecular diagnostics; Patient specific therapy

\section{Introduction}

The human genome project influenced more and more the proteome research field as yet inaccessible due to its immense complexity. This progress increasingly impacts new perspectives in diagnostics and new promising therapy attempts with nucleic acids. They are highly sequence-specific for molecular diagnostics (molecular imaging) and as therapeutic molecules in the individualized patient-specific medicine (targeted therapy). The development of these molecules requires very exigent chemical production methods, like the well-established Diels Alder Reaction (DAR) $[1,2]$ and the DAR with inverse electron demand $\left(\mathrm{DAR}_{\mathrm{inv}}\right)$ with characteristic physico-chemical properties of the $\mathrm{DAR}_{\text {inv }}$ [3-8]. The solid phase peptide synthesis (SPPS), 1963 introduced by Merrifield [9-11] is to be seen as an additional milestone [12-18]. The great scientific and historical importance becomes apparent by the awarded Nobel Prizes for hers works in 1950 and 1984, respectively. Together with Carpino's protection group chemistry [19-25] they can be considered as critical pillars manufacturing of nucleic acids, their derivatives, as well as peptide based active molecules and reformulation of classical drugs.

The synthetic introduction of thiol-groups into nucleic acids permits an oxidative connexion with peptides [26]. These properties also predestine the $\mathrm{DAR}_{\text {inv }}$ as a suitable technology for an intravital ligation of functional components in living systems. As shown here, the synthesis of disulfide-functionalized molecules is possible by use of production techniques like the mercaptane oxidation of different hydrogen sulfide containing molecules [27-29]. We suggest the coupling of SH-groups of terminal cysteines by oxidation and the formation of disulfide-bridges was carried out by use of mild oxidants, but yields of the obtained disulfide-containing molecule are limited and a loss of $60 \%$ must be accepted. At the time a form of bi-functional linkers for the SPPS with a predetermined break-point for enzymatic cleavage in biological systems is still lacking. The use of such a cleavable linker could produce relief for molecular diagnostics and patient specific therapy. Here we illustrate the synthetic route and document the intermediates of the disulfide-bridge containing cell penetrating peptide-based conjugate 7 .

\section{Biological Methods \\ Cell culture}

HeLa human cervix carcinoma cells (DKFZ, Dept. B040) were used. They were maintained at $37^{\circ} \mathrm{C}$ in a $5 \% \mathrm{CO}_{2}$ atmosphere in DMEM (Gibco, Germany), supplemented with $10 \%$ fetal calf serum (Biochrome, Germany).

\section{Treatment of HeLa cervix carcinoma cells}

HeLa cells $\left(4 \times 10^{4}\right)$ were treated in 8 -well Lab-Tek ${ }^{\mathrm{TM}}$ containments $(400 \mu \mathrm{l} /$ well) in cell culture medium with a dilution of the BioShuttle conjugate $7(12.5 ; 25 ; 50 \mu \mathrm{M})$ which was dissolved as stock solution in $50 \%$ acetonitrile $/ \mathrm{H}_{2} \mathrm{O}_{\text {bidest }}$. Cells were grown as subconfluent monolayers in DMEM (control) and the effects were analyzed $24 \mathrm{~h}$ after treatment.

\section{Functionality studies by confocal laser scanning microscopy}

We used the confocal laser scanning microscope (CLSM) of the Microscopy Core Facility of the German Cancer Research Center for qualified verification of the data as follows. The pictures were taken with a Leica confocal microscope TCS SP5 II (objective 40-fold). The

*Corresponding author: Braun K, German Cancer Research Center (DKFZ), Department of Imaging and Radio Oncology, Im Neuenheimer Feld 280, D-69120 Heidelberg, Germany, Tel: +49 6221-42 3329; Fax: +49 6221-42 3326; E-mail: k.braun@dkfz.de

Received October 04, 2013; Accepted January 24, 2014; Published January 31 2014

Citation: Braun K, Wiessler M, Komljenovic D, Schrenk HH, Lorenz P, et al. (2014) Amide-based Disulfide Building Blocks for the Enlargement of the Solid Phase Peptide Synthesis for Molecular Diagnostics and Imaging. Pharmaceut Reg Affairs 3: 115. doi:10.4172/2167-7689.1000115

Copyright: ( 2014 Braun K, et al. This is an open-access article distributed under the terms of the Creative Commons Attribution License, which permits unrestricted use, distribution, and reproduction in any medium, provided the original author and source are credited. 
laser power used for FITC measurements was [green channel: 34\%/1\% $(490 \mathrm{~nm} / 525 \mathrm{~nm})$ and for Rhodamine B measurements [red channel: $3 \% / 81 \%(540 \mathrm{~nm} / 625 \mathrm{~nm})]$, and finally, examined with the Leica LASSoftware. We investigated by fluorescence distribution: 1) the drug uptake into cells, 2) the separation of the bimodal construct into its components and 3) the localization in the cytoplasm.

\section{Chemical Procedures}

\section{Monomer syntheses}

Synthesis of the Fmoc protected cysteamine: The amino group of 2-aminoethanethiol (cysteamine) becomes Fmocprotected by a nucleophilic substitution reaction of $\mathrm{N}-(9$ fluorenylmethoxycarbonyloxy)succinimide with a Fmoc-active ester under interaction of the nitrogen atom with the carbonyl carbon atom. The N-hydroxy-succinimide is separated after amide formation. The addition of the sterically detained N,N-diisopropyl-ethylamine prevents the protonization of the amino group and maintains the nucleophilic character (Scheme 1).

The Fmoc-cysteamine 1 acts as a nucleophilic reaction partner for the following syntheses of the hetero bifunctional disulfide linker.

Cysteamine $\mathrm{HCl}(0.1 \mathrm{~mol})$ and Fmoc-N-hydroxysuccinimidester $(0.11 \mathrm{~mol})$ were dissolved in $100 \mathrm{~mL}$ chloroform and $\mathrm{N}, \mathrm{N}$ diisopropylethylamine (Huenig's base) $(0.1 \mathrm{~mol})$ was added. The solution becomes yellow coloured while stirring overnight. After evaporation a yellow oily solution remained under crystallization at room temperature. The yellow raw product with a stench of sulfur was recrystallized repeatedly in ethanol under addition of charcoal to eliminate clouds originating from colloidal sulfur. The resulting filtrate was rinsed twice in ice-cold ethanol.
Purity and identity of 1 were determined by TLC (Figure 1A) [silica gel plates (Merck, Si-60 with UV indicator $\mathrm{F}_{254}$ ); mobile phase: chloroform/ hexane (4:1); ninhydrin solution] and mass spectrometry. The resulting yield was $63-77 \%$. ESI-MS, m/z: $300.1[\mathrm{M}+\mathrm{H}]^{+}, 317.2$ $\left[\mathrm{M}+\mathrm{NH}_{4}\right]^{+}, 322[\mathrm{M}+\mathrm{Na}]^{+}, 599.2[2 \mathrm{M}+\mathrm{H}]^{+}, 621[2 \mathrm{M}+\mathrm{Na}]^{+}$; molecular formula: $\mathrm{C}_{6} \mathrm{H}_{10} \mathrm{O}_{6} \mathrm{~S}_{2}$.

Synthesis of the 2-carboxyethanthiosulfonic acid-S-2carboxyethyl ester: The synthesis of the dicarboxythiosulfonic acid ester was carried out by oxidation of the 3,3'-dithiodipropanoic acid ester with $\mathrm{H}_{2} \mathrm{O}_{2}$ in glacial acetic acid in which the intermediately emerging peroxyacetic acid acts as an oxidizing agent [30]. Under rapid but mild reaction conditions the first oxidation step results in the thiosulfinic acid ester which was immediately oxidized to the final thiosulfonic acid ester 2 (Scheme 2).

3,3'-dithiodipropionic acid $(0.05 \mathrm{~mol})$ was added to glacial acetic acid in a round bottom flask. Under stirring $2 \% \mathrm{H}_{2} \mathrm{O}_{2}$ was added expeditiously dropwise. Afterwards the flask was heated to $55^{\circ} \mathrm{C}$ in an oil bath. After 45 min a yellow discolouration occurs. After coolingdown a white suspension was observed which, after stirring (1h), a white substance precipitated. The raw product was isolated and dried in a desiccator. The raw product's yield was $45 \%$. After recrystallization in ethanol, the purity and identity were estimated by TLC (Figure 1B) [silica gel plates (Merck, Si-60 with UV indicator $\mathrm{F}_{254}$ ); mobile phase: hexane /ethylacetate $(2: 1)$ in $1 \%$ formic acid; stain reagent: iodine chamber] and mass spectrometry. After threefold recrystallization the resulting yield was 41\%. ESI-MS, m/z: $243[\mathrm{M}+\mathrm{H}]^{+}, 260\left[\mathrm{M}+\mathrm{NH}_{4}\right]^{+}, 265$ $[\mathrm{M}+\mathrm{Na}]^{+}, 485[2 \mathrm{M}+\mathrm{H}]^{+}, 502\left[2 \mathrm{M}+\mathrm{NH}_{4}\right]^{+}, 507[2 \mathrm{M}+\mathrm{Na}]^{+}$; molecular formula: $\mathrm{C}_{6} \mathrm{H}_{1} 0 \mathrm{O}_{6} \mathrm{~S}_{2}$.

Synthesis of the "S-dioxide“ of the N,N'-diacetylcystine dimethyl ester: The first step is the oxidation of the $\mathrm{N}$-acetylcysteine,

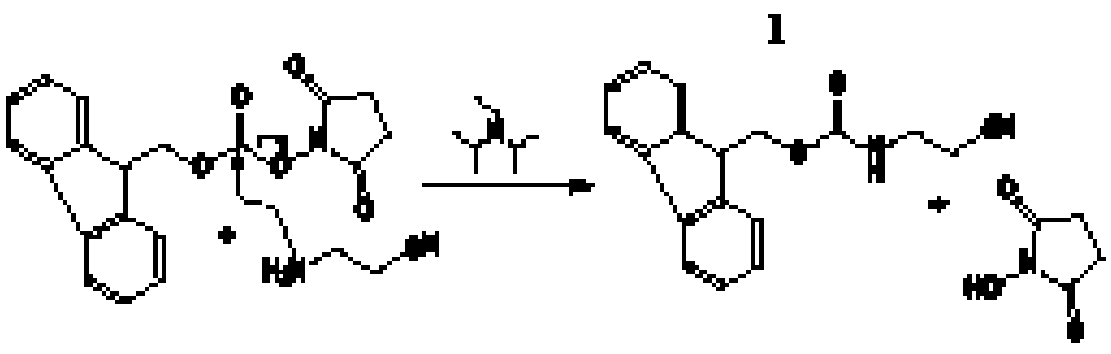

Scheme 1: Illustrates the chemical reaction of the Fmoc active ester with cysteamine to Fmoc-cysteamine 1.

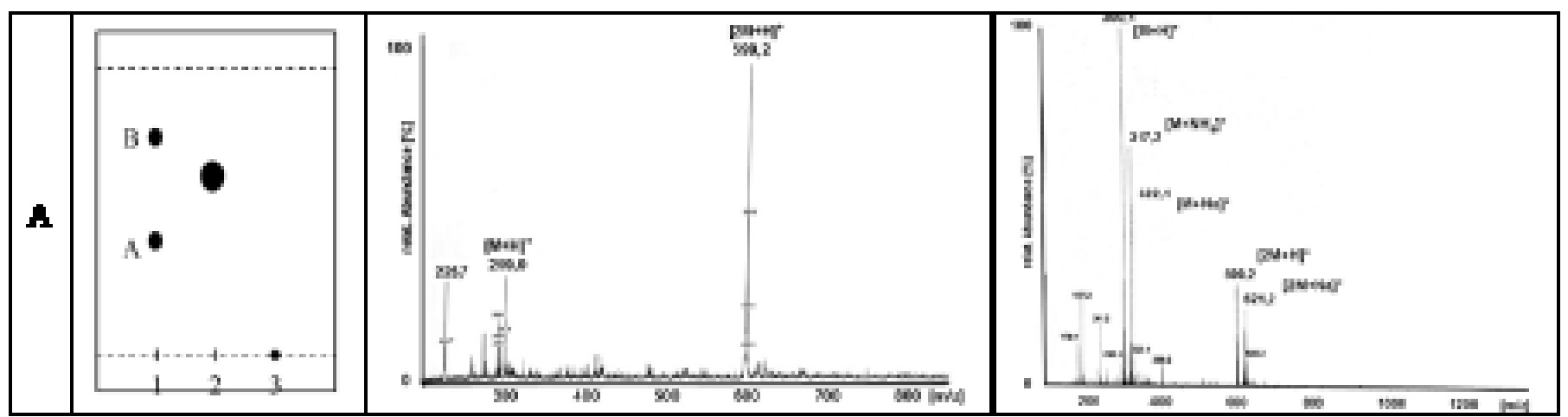

Figure 1A: The TLC (left picture) shows the dot of the raw product after the first recrystallization. Lane 1 represents the product A and B. lane 2 the Fmoc-succinimidyl ester, and lane 3 the cysteamine. The symmetrical disulfide B consists of two lipophilic Fmoc-cysteine monomers which are located near the solvent [chloroform/ hexane $(4: 1)$ ] front in contrast to A whose lipophilic properties are much lower. The middle and right picture illustrate the mass spectrometry graph diagrams. 


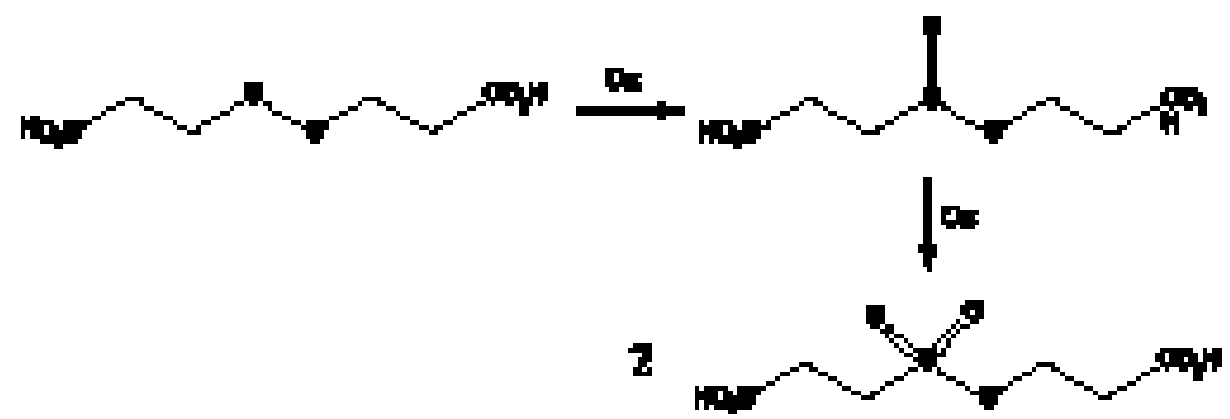

Scheme 2: Demonstrates the oxidation process of the disulfide-dicarbonic acid to the S-dioxide of the 3,3'-dithiopropanonic acid molecule 2.

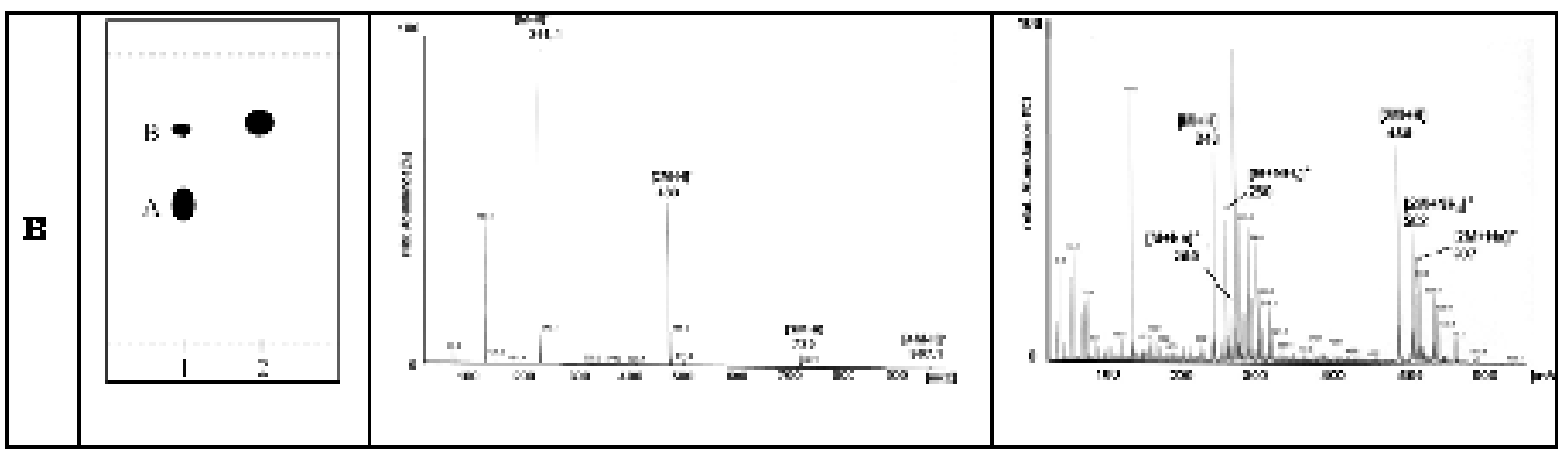

Figure 1B: The TLC (left picture) shows the dots of the reaction product dithiodipropanoic acid (column 2 ) as a reference. Dot $A$ represents the thiosulfonic acid ester. Spot B possesses a similar polarity like the dithiodipropanoic acid. As mobile phase hexane/ethyl acetate (1:2) with formic acid (1\%) were used. The middle and right picture show the MS diagrams of the reaction partners.

mediated by $\mathrm{H}_{2} \mathrm{O}_{2}$, to the corresponding disulfide $\mathrm{N}, \mathrm{N}^{\prime}$-diacetylcystine. The following oxidation step led to the thiosulfinic acid ester and subsequently to the thiosulfonic acid ester 3 . The recrystallization in methanol resulted in the dimethylester 4 (Scheme 3).

In analogy to the dithiodipropionic acid's oxidation process $\mathrm{N}$-acetylcysteine $(0.05 \mathrm{~mol})$ was dissolved in $100 \mathrm{ml}$ glacial acetic acid. Under stirring $10 \mathrm{ml} \mathrm{H}_{2} \mathrm{O}_{2}(30 \%)$ were added dropwise. A quick heating up to $50^{\circ} \mathrm{C}$ initiated an exothermic reaction process up to $80^{\circ} \mathrm{C}$ which was finished after $1 \mathrm{~h}$, then the reaction mixture cooled to room temperature under stirring. After evaporation yellow viscous oil remained which was dissolved in methanol. After hot percolation the mixture cooled down to room temperature. The recrystallization process continued several days at $-10^{\circ} \mathrm{C}$, finally the product 4 was recrystallized again. Purity and identity of 4 were determined by TLC [silica gel plates (Merck, RP18 with UV indicator $\mathrm{F}_{254}$ ); mobile phase: acetonitrile/ water (8:2); stain reagent: iodine chamber] and mass spectrometry (Figure 1C). The yield for the resulting product, calculated as dimethyl ester 4, was $67 \%$. ESI-MS, m/z (pos): $385.1[\mathrm{M}+\mathrm{H}]^{+}, 407.1[\mathrm{M}+\mathrm{Na}]^{+}, 769.2$ $[2 \mathrm{M}+\mathrm{H}]^{+}, 791.2[2 \mathrm{M}+\mathrm{Na}]^{+}$ESI-MS, m/z (neg): $419[\mathrm{M}+\mathrm{Cl}]^{-}, 429.1$ $\left[\mathrm{M}+\mathrm{HCO}_{2}\right] ;, 803.1[2 \mathrm{M}+\mathrm{Cl}] ;$, $813.2\left[2 \mathrm{M}+\mathrm{HCO}_{2}\right]$; molecular formula: $\mathrm{C}_{12} \mathrm{H}_{20} \mathrm{~N}_{2} \mathrm{O}_{8} \mathrm{~S}_{2}$.

Synthesis of the unsymmetrical disulfide linker with 1 and 2: As educts for the chemical reaction to the mixed disulfide linker the Fmoc protected cysteamine 1 and dithiopropanoic acid 2 were used. As illustrated in Scheme 4 the thiolsulfur interacts in a nucleophilic chemical attack in DMF with the S(II) of the thiosulfonic acid under separation of the 3-sulfinicpropionic acid as leaving group. The nucleophilic potential of the thiol group of 1 is sufficient for the disulfide formation, because the S(II) acts electrophilically caused by the strong electron-withdrawing properties of the adjacent $\mathrm{R}-\mathrm{SO}_{2}$ group (Scheme 4).

Equimolar amounts $(10 \mathrm{mmol})$ of 1 and 2 were dissolved in $20 \mathrm{ml}$ DMF in a round bottom flask under stirring for $1 \mathrm{~h}$. Subsequently 10 mmoles sodium bicarbonate were added. The cloudy dissolution was stirred over night. The tenfold-volume amount of $\mathrm{H}_{2} \mathrm{O}$ was added dropwise under precipitation of a yellow-greenish mass of viscous consistency at $4^{\circ} \mathrm{C}$. After filtration and drying the resulting greenish raw product was a solid substance. Purity and identity of 5 were determined by TLC (Figure 1D) [silica gel plates (Merck, Si-60 with UV indicator $\mathrm{F}_{254}$ ); mobile phase: chloroform/ ethanol (4:1); staining reagent: ninhydrin solution] and mass spectrometry. The yield for the resulting product 5 amounted to $68 \%$. ESI-MS, $\mathrm{m} / \mathrm{z}$ (pos): $404.1[\mathrm{M}+\mathrm{H}]^{+}, 426.1$ $[\mathrm{M}+\mathrm{Na}]^{+}, 449.2[\mathrm{M}+2 \mathrm{Na}]^{+}, 829.2[2 \mathrm{M}+\mathrm{Na}]^{+} \mathrm{ESI}-\mathrm{MS}, \mathrm{m} / \mathrm{z}$ (neg): 402.1 [M-H] ; $805.1[2 \mathrm{M}-\mathrm{H}]$; molecular formula: $\mathrm{C}_{20} \mathrm{H}_{21} \mathrm{NO}_{4} \mathrm{~S}_{2}$.

Synthesis of the unsymmetrical disulfide linker with 1 and 3: The synthesis of the disulfide linker 6 was carried out under identical reaction conditions as described above. 1 reacts with the methyl ester derivative of 3. The SH-group of the Fmoc-cysteamine reacts with the $\mathrm{S}$ (II) of the thiosulfonic acid ester under separation of the sulfinic acid of the $\mathrm{N}$-acetylcysteine (Scheme 5).

Eqimolar amounts $(5 \mathrm{mmol})$ of 1 and 4 were dissolved in $20 \mathrm{ml}$ DMF in a round bottom flask under stirring for $1 \mathrm{~h}$. Subsequently, 10 (mmol) sodium bicarbonate were added. The cloudy dissolution was stirred overnight. The tenfold-volume amount of $\mathrm{H}_{2} \mathrm{O}$ was added drop wise under precipitation of a tenacious mass at $4^{\circ} \mathrm{C}$. Before the filtration step the reaction mixture was stirred over 4 hours. The 


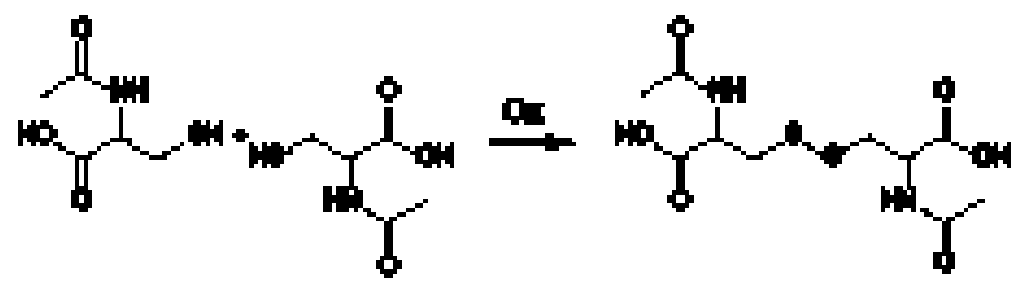

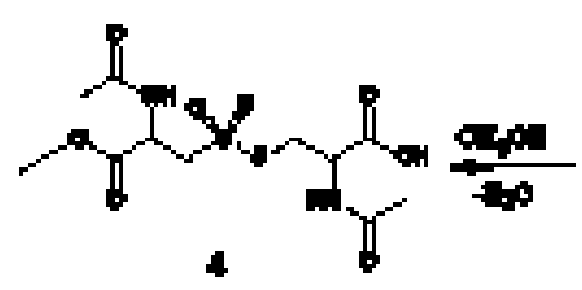

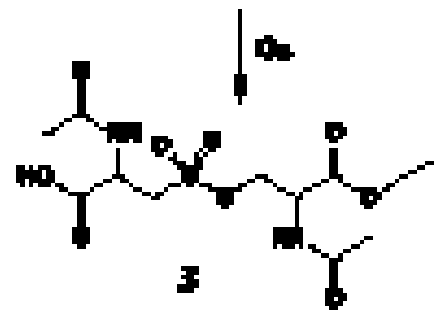

Scheme 3: Illustrates the scheme which exemplifies the oxidation of $\mathrm{N}$-acetylcysteine to the diacetylcysteine and finally to the corresponding "S-dioxide" 3 which reacts with the methanol during the recrystallization procedure to the ester 4.

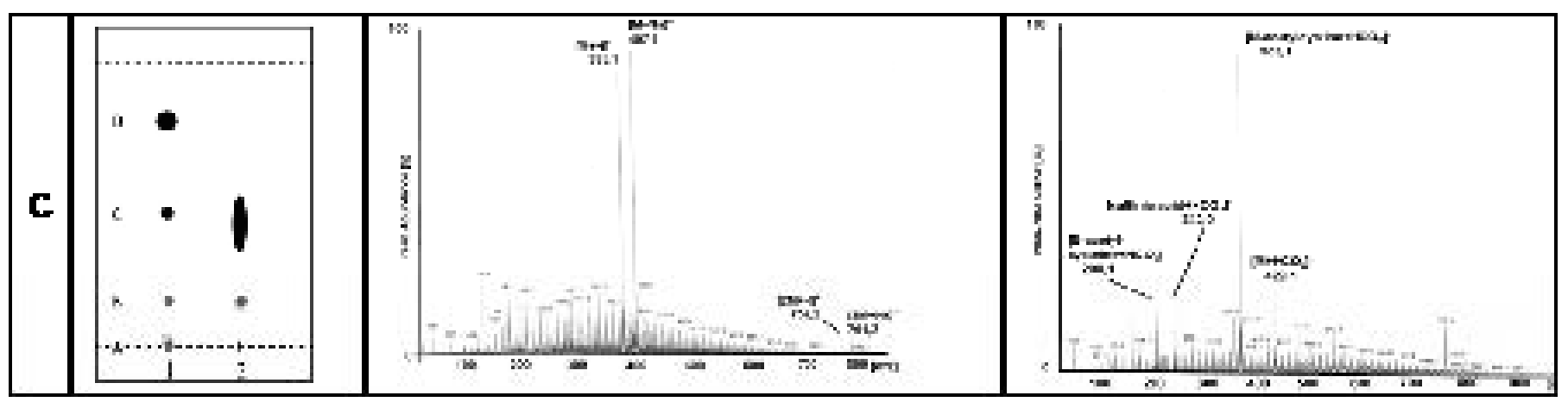

Figure 1C: shows the TLC plot. As polar mobile phase the eluent acetonitrile and $\mathrm{H}_{2} \mathrm{O}$ in a ratio of $8: 2$ were used. As a reference $\mathrm{N}$-acetyl cysteine $\mathrm{A}$ (lane 1) was applied and exhibits several dots, which result from a non optimal concentration of 4 . The lower dot $B$ (less pronounced) represents the oxidized $\mathrm{N}$-acetyl cysteine. The dots $B$ and $C$ are identified in the product probe. The dot $D$ exhibits the highest Rf-value. The middle and right picture shows the MS diagrams of the reaction partners. The measured mol mass 384 corresponds to the mass of the dimethyl ester of the product.

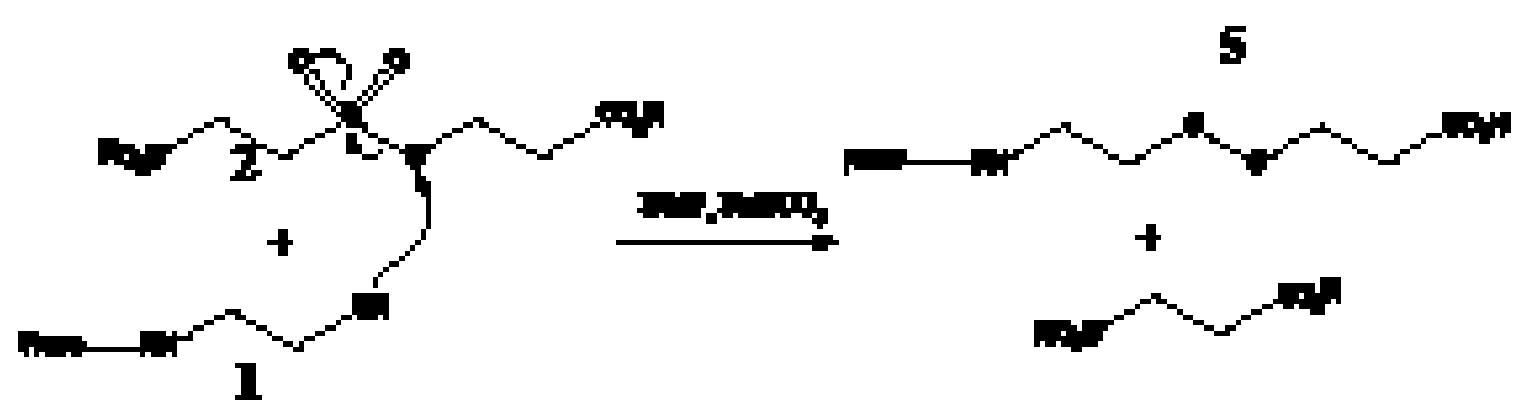

Scheme 4: Fmoc-cysteamine 1 reacts in a nucleophilic substitution reaction with the thiosulfonic acid ester 2 to the mixed products disulfide 3-[(2-\{((9H-fluoren-9-yl) methoxy)carbonyl)amino)ethyl\}disulfanyl]propanoic acid 5 and to the sulfinopropanoic acid.

resulting raw product was dried and subsequently analyzed. Purity and identity of $\mathbf{6}$ were determined by TLC [silica gel plates (Merck, Si-60 with UV indicator $\left.\mathrm{F}_{254}\right)$; mobile phase: chloroform/ ethanol (9:1) in formic acid 1\%; ninhydrin solution] and mass spectrometry (Figure 1E). The resulting yield was $95 \%$. ESI-MS, $\mathrm{m} / \mathrm{z}$ (pos): $475.1[\mathrm{M} 1+\mathrm{H}]^{+}$, $497[\mathrm{M} 1+\mathrm{Na}]^{+}, 949.3[2 \mathrm{M} 1+\mathrm{H}]^{+}, 971.2[2 \mathrm{M} 1+\mathrm{Na}]^{+} ; \mathrm{ESI}-\mathrm{MS}, \mathrm{m} / \mathrm{z}$ (neg): $459.1[\mathrm{M} 2-\mathrm{H}]^{-}, 509.1[\mathrm{M} 1+\mathrm{Cl}]^{-}, 511.1\left[\mathrm{M} 1+\mathrm{HCO}_{2}\right]$; 919.2 [2M2$\mathrm{H}]^{-}, 933.2[\mathrm{M} 1+\mathrm{M} 2-\mathrm{H}]^{-}, 983.2[2 \mathrm{M} 1+\mathrm{Cl}]^{\prime} ;$ molecular formula $\mathrm{M} 1$ : $\mathrm{C}_{23} \mathrm{H}_{26} \mathrm{~N}_{2} \mathrm{O}_{5} \mathrm{~S}_{2} ; \mathrm{M} 2: \mathrm{C}_{22} \mathrm{H}_{24} \mathrm{~N}_{2} \mathrm{O}_{5} \mathrm{~S}_{2}$.
Solid phase peptide Synthesis - SPPS: The functional peptide Rhodamine B-GRQIKIWFQNRRMKWKK-[3-(2-aminoethyl)disulfanylpropanoic acid]-VKRKKKPKK(FITC)R 7 was synthesized in an automated multiple synthesizer Syro II (MultiSyn Tech, Germany) using the Fmoc chemistry under atmospheric conditions at room temperature as follows: 0.25 micromol of Fmoc-L-Arg(Pmc)-HMPB-ChemMatrix ${ }^{\circ}$ resin loading $0.50 \mathrm{mmol} / \mathrm{g}$. Lysine 27 was protected with the selective protectinggroup1-(4,4-di-methyl-2,6-dioxocyclohex-1-yliden)ethyl(Dde). For coupling amino acids a fivefold excess of the Fmoc-protected 


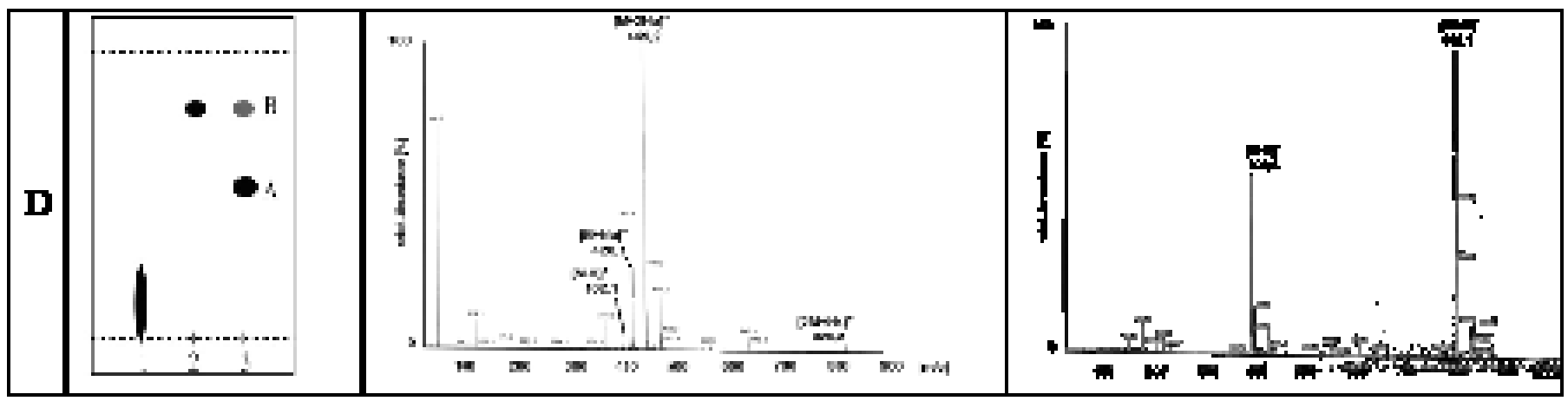

Figure 1D: The TLC of the reaction mixture shows the raw product as well as the educts. As mobile phase eluent chloroform/ethanol (4:1) was used. As a reference the educts were used S-dioxide of the dithio propanoic acid (spot in lane 1) and Fmoc-cysteamine (lane 2). Position 3 represents the product mixture and shows a dot at the identical Rf-value of 2 . A second dot (A) is located between the start and the solvent front. The measured mass of 597 suggests a disulfide of the Fmoccysteamine. The middle and right picture depict mass spectrographs indicating a molecule with a molecular weight of 403 which corresponds exactly the desired product's calculated mol mass of 403.52.L.
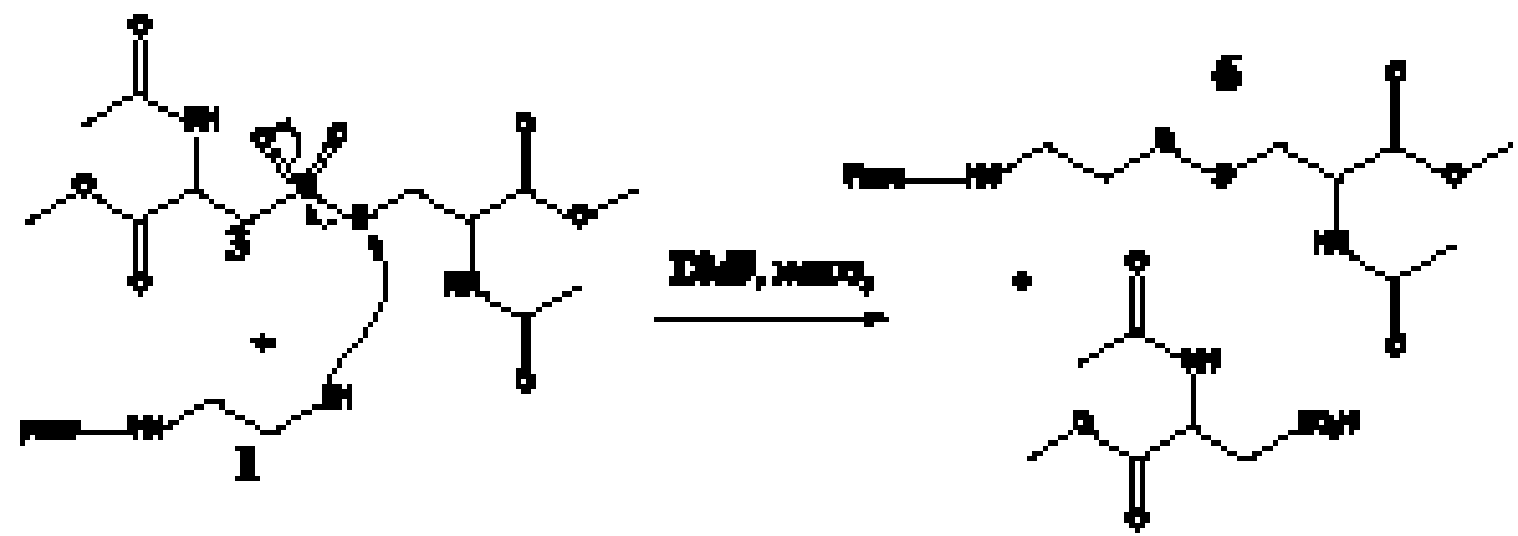

Scheme 5: The Fmoc-cysteamine 1 reacts in a nucleophilic substitution reaction with the thiosulfonic acid ester 3 to the mixed disulfide 6 and the sulfinic acid.

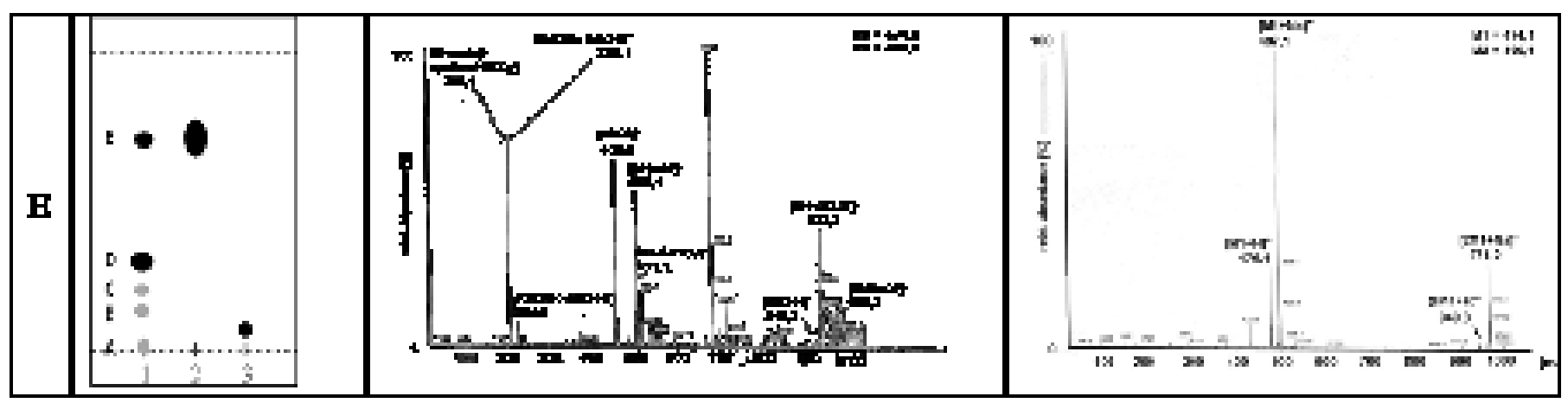

Figure 1E: TLC of raw product 6 and the educts. As mobile phase eluent chloroform/ ethanol $(9: 1)$ in formic acid $1 \%$ was used. In track 1 the spot $D$ represents the raw product 6 and spots A-E. Track 2 shows the spot $\mathrm{E}$ and represents the Fmoc-cysteamine 1 . Track 3 shows the spot of the oxidation product of the $\mathrm{N}$-acetylcysteine.

amino acid was activated in situ with 5 equivalents 2-(1H-benzotriazole-1-yl)-1,1,3,3-tetramethyluronium hexafluorophosphate (HBTU) and N,N-diisopropylethylamine (DIPEA) $(0.5 \mathrm{M})$ in N,N-dimethylformamide (DMF). The coupling reaction period was $40 \mathrm{~min}$. Afterwards, the Fmoc-group was cleaved with piperidine (20\%) in DMF for $3 \mathrm{~min}$ and $10 \mathrm{~min}$ respectively. After each step the resin was washed 5 times with DMF. The Rhodamine B marker \{[9-(2-carboxyphenyl)6-diethylamino-3-xanthenylidene]-diethylammonium chloride)\} was inserted into the peptide by a manual coupling procedure. A threefold excess of this marker was activated in situ with 3 equivalents of O-(7-
azabenzotriazol-1-yl)-N,N,N', $\mathrm{N}^{\prime}$-tetramethyluronium hexafluorophosphate (HATU) and 2 equivalents DIPEA, then added to the resin bound peptide for one hour reaction time. The resin was then washed three times with DMF. The Dde-protecting group was cleaved with $4 \%$ hydrazine in DMF and the FITC \{2-[6-hydroxy-3-oxo- $(3 \mathrm{H})$-xanthene-9-yl]-benzoic acid $\}$ was coupled with the standard procedure. The resin was edulcorated with DMF, dichloromethane (DCM) and isopropanol, and finally dried. The following separation of the peptide from the resin and of the side chain protecting groups was performed with trifluoroacetic acid (TFA) (90\%) and as a scavenger triethylsilane/ 
water $(2.5 \% / 2.5 \%)$ was used in the length of time of $2.5 \mathrm{~h}$ at room temperature.

Purification of the double labelled B-bioshuttle-conjugate: The crude material was purified by preparative HPLC on a Kromasil 100C18-10 $\mu \mathrm{m}$ reverse phase column $(30 \times 250 \mathrm{~mm})$ using an eluent of $0.1 \%$ trifluoroacetic acid in water $(\mathrm{A})$ and $80 \%$ acetonitrile in water (B). The end product, Rhodamine-B-BioShuttle-S-S-NLS-FITC conjugate (hereinafter called double labelled BioShuttle conjugate) 7, was eluted with a successive linear gradient of $10 \% \mathrm{~B}$ to $80 \% \mathrm{~B}$ in $30 \mathrm{~min}$ at a flow rate of $23 \mathrm{ml} / \mathrm{min}$. The fractions containing the purified peptide were lyophilized. The purified material was characterized with analytical HPLC and matrix assisted laser desorption mass spectrometry (Figure 1F). Yield 9.8mg (8.6\%) (MALDI-MS); m/z: 4296.31 (100.0\%), 4295.30 (98.2\%), 4297.31 (84.4\%), 4298.31 (66.1\%), 4294.30 (39.3\%), 4297.30 (38.0\%), 4296.30 (31.2\%), 4299.31 (27.9\%), 4298.30 (24.1\%), 4299.32
$(17.3 \%), 4300.31(8.9 \%), 4300.32(7.0 \%), 4301.31(5.4 \%), 4299.30$ (5.2\%), 4300.30 (4.1\%), 4297.29 (1.4\%), 4301.30 (1.1\%), 4299.29 (1.1\%). exact mass: 4294,30; chemical formula: $\mathrm{C}_{209} \mathrm{H}_{310} \mathrm{~N}_{55} \mathrm{O}_{36} \mathrm{~S}_{4}^{+}$(Scheme 6) (Figure 1).

\section{Results and Discussion}

The use of such cleavable linkers could become very important for easier and faster molecular diagnostics and patient specific therapy.

Here we show the synthesis steps and characterization of our disulfide linkers to gain double labelled BioShuttle conjugates exemplarily.

Unsymmetrical disulfide linkers and double labelled bioshuttle conjugates

(Table 1)

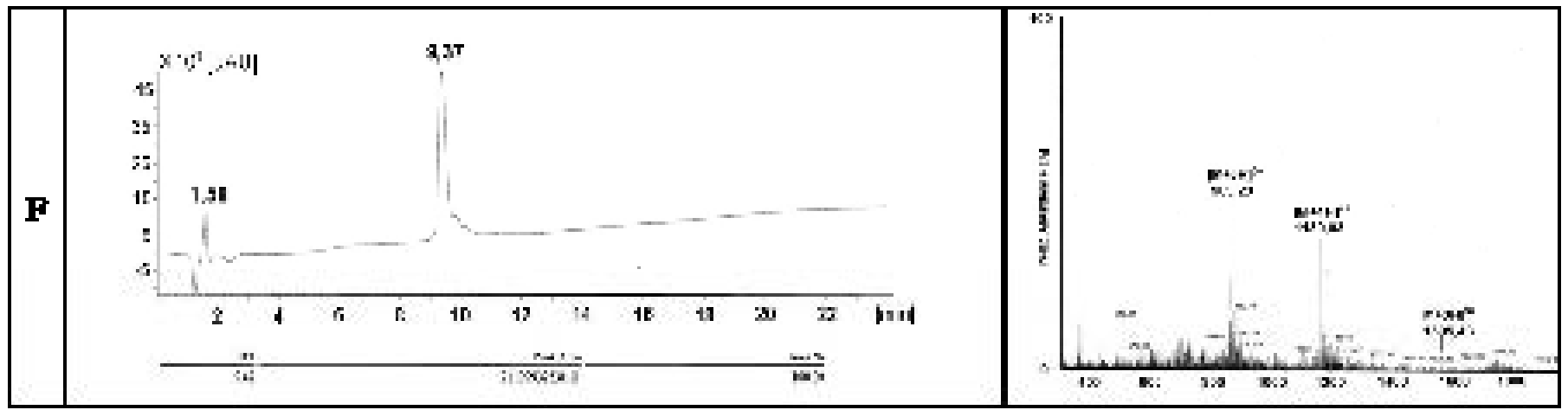

Figure 1F: shows the HPLC (left). The peak was measured at $9.4 \mathrm{~min}$. The MS spectrograph demonstrates the identity of the reaction product 7 . The chemical structure is illustrated in scheme 6.

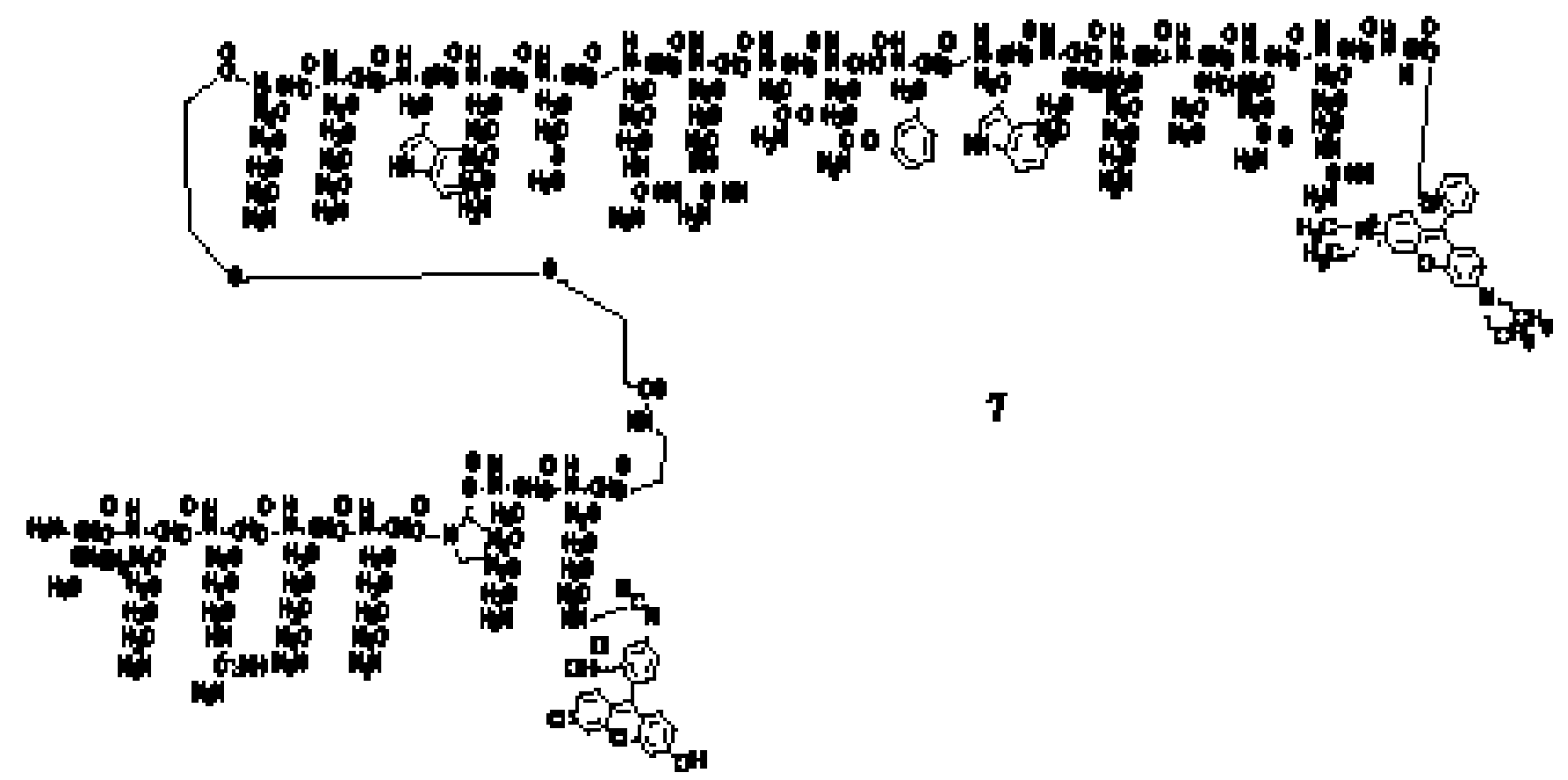

Scheme 6: Illustrates the amino acid sequences of the double labeled complete BioShuttle conjugate 7 . Here the investigated unsymmetrical disulfide linker [3-(2-aminoethyl)-disulfanylpropanoic acid] 6, connects the cell membrane transport facilitating peptide module (CPP), at whose C-terminus the xanthene dye Rhodamine $B$ is attached. The nuclear localization sequence (NLS) module harboring a lysine spacer whose $\varepsilon$-amino group in turn is functionalized with the fluorescein isothiocyanate dye FITC by thiocarbamide formation. 


\section{Cell localization studies of the bioshuttle conjugate by CLSM}

To ensure the functionality of the disulfide monomer $\mathbf{5}$, HeLa cervix carcinoma cells were treated with the double labelled BioShuttle conjugate 7 (Table 1). The picture A in Figure 2 shows HeLa cells which offer the merged fluorescence signals (orange color) of the red and green channel (not displayed) $15 \mathrm{~min}$ after incubation $(12.5 \mu \mathrm{M}$ final concentration) with the double labelled BioShuttle conjugate 7 in the cytoplasm and perinuclearly with the exception of the nucleus.

Picture B (Figure 2) depicts the superposition of C and D and illustrates the spatial fluorescence signal distribution inside of the HeLa cells 30 min after incubation. Mixed fluorescence signals (yelloworange colored) are visible in speckles as well as in particular small ranges scattered close to the cell membrane. Green fluorescence signals are already distinguishable over the whole intracellular range including the cell nucleus compared to the intercellular space. The pictures representing both the red $\mathrm{C}$ and green $\mathrm{D}$ channel can confirm these observations (bottom leaf of the Figure 2).

Using these methodologies a local enrichment of "old fashioned" drugs' and/or imaging molecules inside of target cells are possible. The solid phase peptide synthesis (SPPS) is considered as an increasing key technology in the organic-preparative chemistry, in biochemistry and in the pharmaceutical drug development. The specific advantages like the possible automation, the excellent yields, and tailored multifaceted applications turn the SPPS into an indispensable tool in the peptide synthesis and in the synthesis of (bio)-polymers. The development of modern patient-specific pharmaceutics requires efficiency under minimalization of undesired adverse reactions. This demands chemical technologies like efficient ligation well documented as "Click Chemistry" $[1,31,32]$ and proper synthesis methodologies, represented by SPPS combined with the protection group chemistry, introduced by Merriefield [10] and Carpino [25]. Based on these key technologies, a synthesis of functional peptides for transport of active molecules and imaging substances across biological barriers, like cell membranes, nuclear envelope, as well as the synthesis of nucleic acidbased polymers is possible [33-40]. The combination of functional molecules demands covalent and/or cleavable ligations.

Unfortunately the yields of these cleavable disulfide-molecules are limited (loss of 60\%).

Despite the selectivity of the oxidation reactants symmetrical and asymmetrical disulfide molecules are found simultaneously. Therefore additional purification steps are required and result in a dissipation of material. One further problem is that safe coupling methods are lacking, particularly with regard to the insertion of a cleavable linker, already during peptide synthesis. At the moment appropriate hetero bi-functional linkers with a predetermined break-point for enzymatic cleavage are still lacking for the SPPS.

However, we could circumvent this by the selective ligation of the requested functional modules. But each reaction step coincided with a loss of yield, especially the disulfide bridge formation statistically tops out at $30 \%$ yield. Therefore the extent of chemical reactions should be minimized imperatively; the use of building blocks with a disulfide group could circumvent this handicap and help to develop active components connected to an enzymatically cleavable disulfide-bridge.

Aiming at a better understanding of synthesis-based pitfalls and

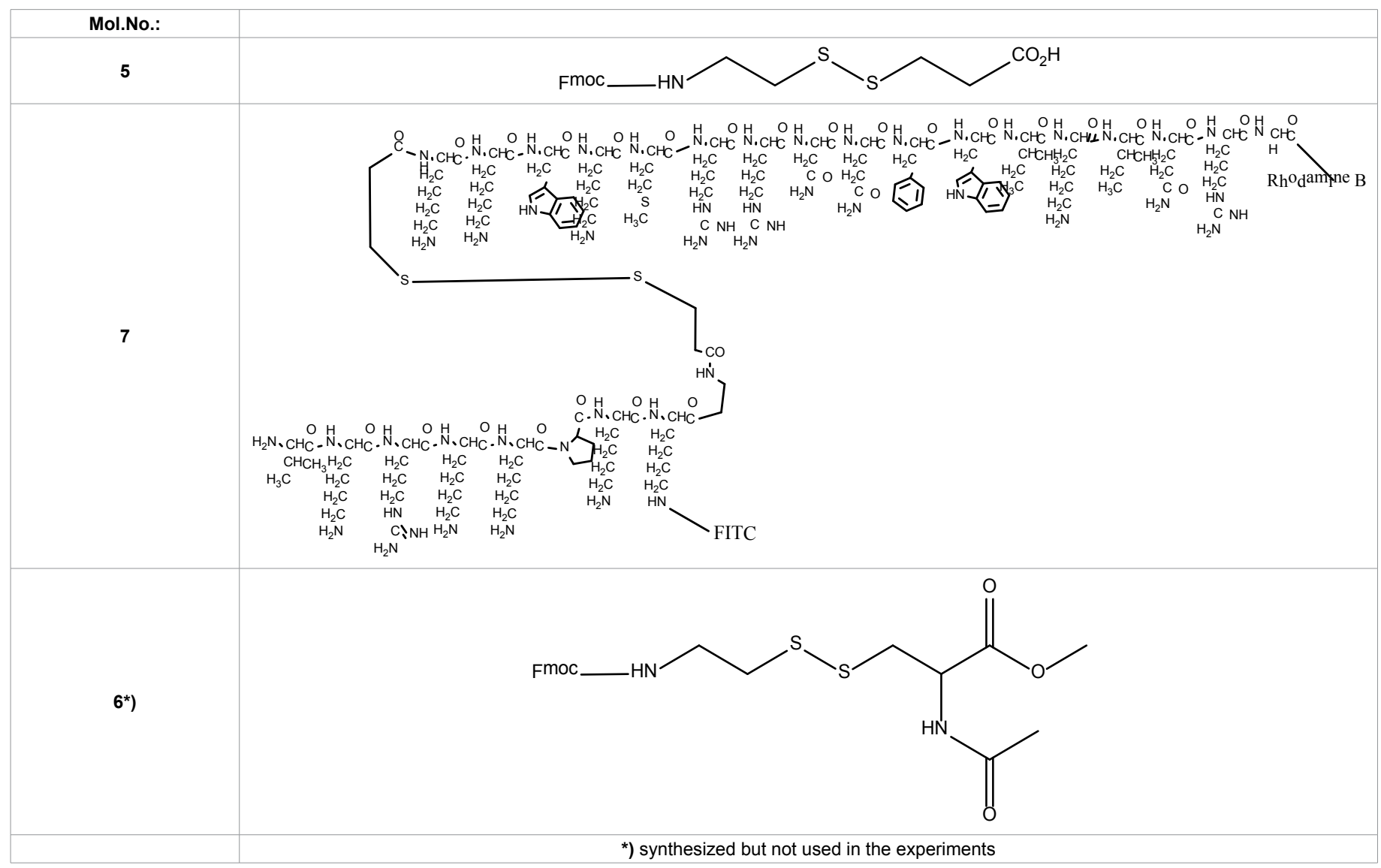

Table 1: Lists the synthesized Fmoc-protected disulfide monomers 5 and 6 , wherein 5 was employed for the design and the functionality of the double labelled BioShuttle conjugate 7 . 

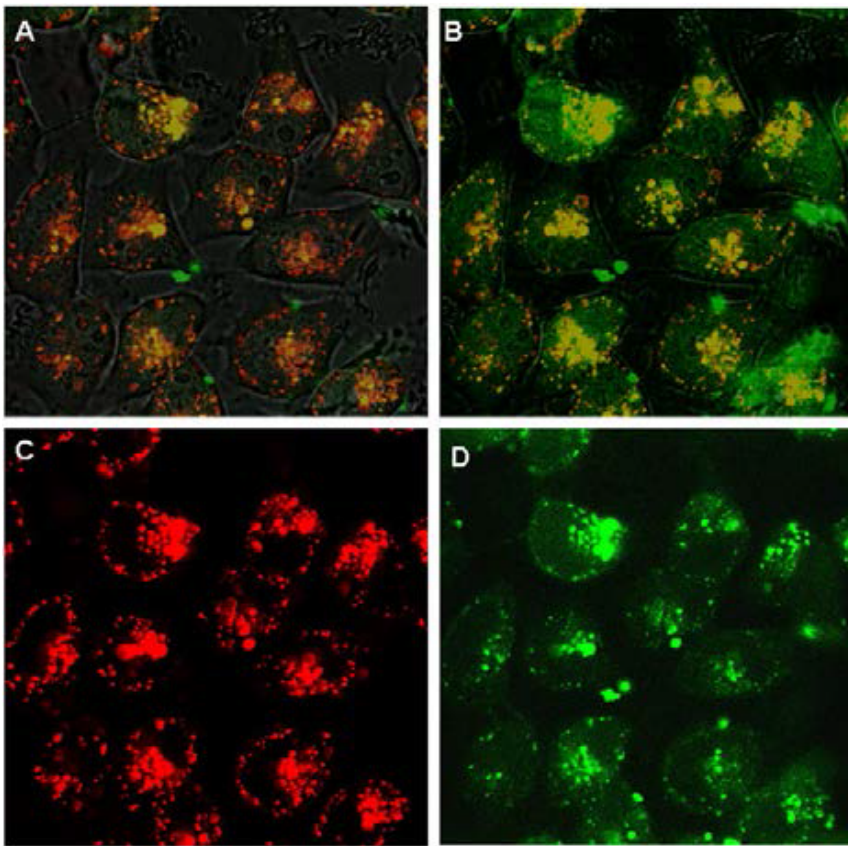

Figure 2: A: shows CLSM pictures of HeLa cervix carcinoma cells, after 15 min application of the double labelled BioShuttle conjugate 7.

$\mathrm{B}$ : CLSM picture after $30 \mathrm{~min}$ incubation

C: separated green channel FITC at $457 \mathrm{~nm}$ (excitation)

D: separated red channel Rhodamine B at $543 \mathrm{~nm}$ (excitation).

unexpected reaction processes, the design of components as well as their characteristics was highlighted under different aspects as follows:

An analysis of the Fmoc-cysteamine synthesis (Figure 1A) exhibited two products with the MW 597 (B) and 299 (A). The latter mass represents the reaction product Fmoc-cysteamine 1. The TLC flow properties of the first product proved a less polar behavior. Resulting from lipophilic properties after disulfide formation of 1 , its dot is shown near the solvent front. This oxidation process was run under atmospheric oxygen, but in order to avoid this undesired reaction in the future, the chemical reaction should be expedited under oxygen exclusion giving higher yields of 1 would be expected (Figure 1B).

Another reaction led to the S-dioxide of the 3,3'-dithiopropionic acid molecule 2. Mass spectrometry measurements found the reaction product with the MW 242 and the TLC exhibits two different dots in lane 1 . Dot $\mathrm{A}$ is characterized by a relatively high polarity originating from the two oxygen atoms suggesting the oxidized dithiopropionic acid.

The aimed reaction product 2 is the S-Dioxide of the $\mathrm{N}^{\mathrm{N}} \mathrm{N}^{\mathrm{c}}$ diacetylcystine dimethyl ester should reveal a high polarity caused by the twofold oxidized sulfur. However, against all expectation, flow behaviour in the TLC (Figure 1C) is shown, which corresponds to a reduced polarity explainable by an esterification process, which is substantiated by the mass spectrometry data. We identified a molecule with $384 \mathrm{MW}$, corresponding to the MW of the dimethyl ester of the product. It is accepted, that N-protected amino acids dissolved in $\mathrm{MeOH}$ react with thionyl chloride or with hydrochloric acid to the corresponding ester, but the identical reaction without catalysis in acidic solution is still unclear. Also the reaction conditions during the MS measurements could be responsible for it. The existence of further reaction products suggests sulfinic and sulfonic acid derivatives of the
N-acetylcysteine whose methyl esters have the MWs of 195, 209, 211 and 225 .

The TLC of the reaction products (Figure 1D), according to Scheme 4 , presents first analytical information like dots of the Fmoc-cysteamine (lane 2) and the S-dioxide of the dithiopropanoic acid (track 1) as well as still unexplained dots like the spot A. This is located in the middle between the start point and the mobile phase eluent front, which represents a reaction fraction of incompletely reacted Fmoc-cysteamine with thiosulfonic acid. One further assumption could be the existence of a disulfide of two Fmoc-cysteines, which offer nearly identical $R_{f}$ values under the used chromatography protocol. We confirmed this suspicion with mass spectrometry data indicating substances with the MW 597, which is the disulfide of the Fmoc-cysteamine and with the MW 403 giving the desired reaction product 5 with a calculated mass of 403.53 .

The TLC in Figure 1E shows the different dots in lane 1 (reaction mixture), lane 2 represents the Fmoc-cysteamine. As a further reference the oxidation product of the $\mathrm{N}$-acetyl cysteine was used (track 3 ). Whereas the dot $\mathrm{E}$ of the track 1 corresponds to the dot of track 2, the depiction of the residual dots remains to speculate. Most likely dot A could be the cysteine sulfonic acid, whose molecular mass of 225 was detected (calculated mass 225.22 of 2-acetyl amino-3-sulfo propanoic acid methyl ester) by the negative mode of the mass spectrometry. The dots $\mathrm{B}$ and $\mathrm{C}$ are less pronounced, which suggests lower concentrations of the substances in the reaction mixture. The low $\mathrm{R}_{\mathrm{f}}$-values allow the assumption for a polarity; in view of this fact mass analysis data show fragments with the MWs: 369 and 208, which could correspond to the calculated mass of [N-acetylcystine $\left.+\mathrm{HCO}_{2}\right]^{-}$is 369.1 and to the mass of 2-acetyl amino-3-sulfino-propanoic acid methyl ester. In addition to diverse hydrolysis fragments, as shown in position 1, the spot D suggests the desired reaction product 6 (Figure 1F), which may be present as a free acid with the MW of 459 , although the educt exists as the corresponding methyl ester suggesting tentative hydrolysis effects.

Here, we like to emphasize that the use of this new building block 6 is not only restricted to therapeutic tools but also useful in the diagnostic field, for a clinical practice in MRT, CT and PET. A use of this monomer is possible by functionalizing it with imaging molecules. This objective could be an improvement of precision for a better differentiation of a target tissue and the surrounding healthy tissue and thus for a therapeutic success which may lead.

\section{References}

1. 1951 [Otto Diels and Kurt Alder; winners of the Nobel Prize in chemistry]. Cienc Invest 7: 143-144.

2. Bachmann WE, Chemerda JM (1948) The Diels-Alder reaction of 1-vinyl-6methoxy-3,4-dihydronaphthalene with citraconic anhydride. J Am Chem Soc 70: 1468-1473.

3. Blackman ML, Royzen M, Fox JM (2008) Tetrazine ligation: fast bioconjugation based on inverse-electron-demand Diels-Alder reactivity. J Am Chem Soc 130 13518-13519.

4. Waldeck W, Wiessler M, Ehemann V, Pipkorn R, Spring H, et al. (2008) TMZBioShuttle--a reformulated temozolomide. Int J Med Sci 5: 273-284.

5. Ibrahim-Ouali M (2009) Diels-Alder route to steroids and associated structures Steroids 74: 133-162.

6. Carboni RA, Lindsey RV (1959) Reactions of Tetrazines with Unsaturated Compounds - A New Synthesis of Pyridazines. J Am Chem Soc 81: 4342-4346.

7. Sauer J, Wiest H (1962) Diels-Alder-Additionen Mit Inversem Elektronenbedarf Angewandte Chemie 74: 353.

8. Wiessler M, Waldeck W, Kliem C, Pipkorn R, Braun K (2009) The Diels-Alderreaction with inverse-electron-demand, a very efficient versatile click-reaction 
Citation: Braun K, Wiessler M, Komljenovic D, Schrenk HH, Lorenz P, et al. (2014) Amide-based Disulfide Building Blocks for the Enlargement of the Solid Phase Peptide Synthesis for Molecular Diagnostics and Imaging. Pharmaceut Reg Affairs 3: 115. doi:10.4172/2167-7689.1000115

concept for proper ligation of variable molecular partners. Int J Med Sci 7: 1928.

9. Merrifield B (1986) Solid phase synthesis. Science 232: 341-347.

10. Merrifield RB (1963) Solid Phase Peptide Synthesis. I .The Synthesis of a Tetrapeptide. J Am Chem Soc 85: 2149-2154.

11. Merrifield B (1997) Concept and early development of solid-phase peptide synthesis. Methods Enzymol 289: 3-13.

12. Ball HL, Mascagni $P$ (1996) Chemical synthesis and purification of proteins: a methodology. Int J Pept Protein Res 48: 31-47.

13. Cavallaro V, Thompson P, Hearn M (2001) Solid-Phase synthesis of a dendritic peptide related to a retinoblastoma protein fragment utilizing a combined bocand fmoc-chemistry approach. J Pept Sci 7: 262-269.

14. Moss JA (2005) Guide for resin and linker selection in solid-phase peptide synthesis. Curr Protoc Protein Sci Chapter 18: Unit 18

15. Sabatino G, Papini AM (2008) Advances in automatic, manual and microwaveassisted solid-phase peptide synthesis. Curr Opin Drug Discov Devel 11: 762 770 .

16. Bayer O, Houben J, Muller E (1974) Methoden der organischen Chemie 'Houben-Weyl'. Stuttgart.

17. Christensen L, Fitzpatrick R, Gildea B, Petersen KH, Hansen HF, et al. (1995) Solid-phase synthesis of peptide nucleic acids. J Pept Sci 1: 175-183.

18. Chantell CA, Onaiyekan MA, Menakuru M (2012) Fast conventional Fmoc solid-phase peptide synthesis: a comparative study of different activators. J Pept Sci 18: 88-91.

19. Juan L, Jishen Z, Fei S, Gemin F, Qingxiang G, et al. (2007) Chemical synthesis of proteins. Progress in Chemistry 19: 1866-1882.

20. Amblard M, Fehrentz JA, Martinez J, Subra G (2006) Methods and protocols of modern solid phase Peptide synthesis. Mol Biotechnol 33: 239-254.

21. Codee JDC, Ali A, Overkleeft HS, van der Marel GA (2011) Novel protecting groups in carbohydrate chemistry. Comptes Rendus Chimie 14: 178-193.

22. Somoza A (2008) Protecting groups for RNA synthesis: an increasing need for selective preparative methods. Chem Soc Rev 37: 2668-2675.

23. Carpino LA, Ghassemi S, Ionescu D, Ismail M, Sadat-Aalaee D, et al. (2003) Rapid, continuous solution-phase peptide synthesis: Application to peptides of pharmaceutical interest. Organic Process Research \& Development 7: 28-37.

24. Atherton E, Sheppard RC. The fluorenylmethoxycarbonyl amino protecting group. In: Undenfriend S, Meienhofer J, editors. The Peptides. New York: Academic Press; 1987; p. 1-38.
25. Carpino LA, Han GY(1972) The 9-Fluorenylmethoxycarbonyl Amino-Protecting Group. J Org Chem 37: 3404-3409.

26. Muratovska A, Eccles MR (2004) Conjugate for efficient delivery of short interfering RNA (siRNA) into mammalian cells. FEBS Lett 558: 63-68.

27. Yoneda F, Suzuki K, Nitta Y (1967) A New Hydrogen-Abstracting Reaction with Diethyl Azodicarboxylate. J Org Chem 32: 727-729.

28. Kosower NS, Kosower EM, Wertheim B, Correa WS (1969) Diamide, a new reagent for the intracellular oxidation of glutathione to the disulfide. Biochem Biophys Res Commun 37: 593-596.

29. Evans BJ, Doi JT, Musker WK (1990) Kinetics of the Aqueous PeriodateOxidation of Aliphatic Disulfides and Thioethers. J Org Chem 55: 2580-2586.

30. Moore TL, Oconnor DE (1966) The Reaction of Methanesulfenyl Chloride with Alkoxides and Alcohols. Preparation of Aliphatic Sulfenate and Sulfinate Esters. Journal of Organic Chemistry 31: 3587-3592.

31. Kolb HC, Finn MG, Sharpless KB (2001) Click Chemistry: Diverse Chemica Function from a Few Good Reactions. Angew Chem Int Ed Engl 40: 2004-2021.

32. Wiessler M, Kliem C, Lorenz P, Mueller E, Fleischhacker H. EU Patent: Ligation reaction based on the Diels Alder Reaction with invers electron demand.

33. Langel U, Pooga M, Bartfai T (1997) Cell Penetrating PNA Constructs. J NEUROCHEM 69: 260.

34. Holm T, Andaloussi SE, Langel U (2011) Comparison of CPP uptake methods. Methods Mol Biol 683: 207-217.

35. Braun K, Wiessler M, Ehemann V, Pipkorn R, Spring H, et al. (2008) Treatment of glioblastoma multiforme cells with temozolomide-BioShuttle ligated by the inverse Diels-Alder ligation chemistry. Drug Des Devel Ther 2: 289-301.

36. Braun K, Peschke P, Pipkorn R, Lampel S, Wachsmuth M, et al. (2002) A biological transporter for the delivery of peptide nucleic acids (PNAs) to the nuclear compartment of living cells. J Mol Biol 318: 237-243.

37. Wiessler M, Hennrich U, Pipkorn R, Waldeck W, Cao L, et al. (2011) Theranostic cRGD-BioShuttle Constructs Containing Temozolomide- and Cy7 For NIRImaging and Therapy. Theranostics 1: 381-394.

38. Rush J, Bertozzi CR (2006) An alpha-formylglycine building block for fmocbased solid-phase peptide synthesis. Org Lett 8: 131-134.

39. Gante J (1994) Peptidomimetics - Tailored Enzyme-Inhibitors. Angewandte Chemie-International Edition in English 33: 1699-1720.

40. Field L, Khim YH (1972) Organic disulfides and related substances. 33 Sodium 4-(2-acetamidoethyldithio) butanesulfinate and related compounds as antiradiation drugs. J Med Chem 15: 312-315. 